Abstract 1303 Table 2 Outcomes within 10 years of follow-up. Values are expressed as mean \pm SD or $n(\%)$

\begin{tabular}{llll}
\hline Outcomes & $\begin{array}{l}\text { EULAR/ACR score } \\
<20 ~ N=415\end{array}$ & $\begin{array}{l}\text { EULAR/ACR score } \\
\geq 20 \mathrm{~N}=452\end{array}$ & P value \\
\hline Death & $24(5.8)$ & $44(9.7)$ & 0.03 \\
Time to death, years & $5.0 \pm 2.9$ & $3.6 \pm 3.1$ & 0.07 \\
Increase in SDI $^{\mathrm{a}}$ & $167(40)$ & $210(46)$ & 0.02 \\
Time to SDI $^{\mathrm{a}}$ increase, years & $2.9 \pm 2.7$ & $3.0 \pm 2.9$ & 0.52 \\
SDI $^{\text {a }}$ score & \\
SDI $^{\mathrm{a}}$ Domains & & & \\
Ocular & $0.97 \pm 1.42$ & $1.28 \pm 1.47$ & 0.03 \\
Neurologic & & & \\
Renal & $20(10.26)$ & $34(15.96)$ & 0.08 \\
Pulmonary & $19(9.74)$ & $28(13.15)$ & 0.28 \\
Cardiovascular & $5(2.56)$ & $19(8.92)$ & 0.006 \\
Vascular & $3(1.54)$ & $9(4.23)$ & 0.10 \\
Gastrointestinal & $22(11.28)$ & $14(6.57)$ & 0.09 \\
Muskuloeskeletal & $6(3.08)$ & $8(3.76)$ & 0.70 \\
Skin & $5(2.56)$ & $6(2.82)$ & 0.87 \\
Gonadal & $38(19.49)$ & $54(25.35)$ & 0.15 \\
Diabetes & $18(9.23)$ & $21(9.86)$ & 0.82 \\
Malignancy & $1(0.51)$ & $3(1.41)$ & 0.35 \\
\hline At & $3(1.54)$ & $14(6.57)$ & 0.01 \\
& $5(2.56)$ & $3(1.41)$ & 0.40 \\
\hline
\end{tabular}

${ }^{\#}$ At 10 years of follow-up, $\mathrm{N}=190$ and 206 in the low and high score groups respectively. asLICC/ACR Damage Index

Abstract 1303 Table 3 Univariate and Multivariable Cox Regression analysis. Factors associated with damage accrual and death within 10 years of follow-up

\begin{tabular}{|c|c|c|c|c|}
\hline & \multicolumn{2}{|c|}{ Univariate Cox Regression } & \multicolumn{2}{|c|}{$\begin{array}{l}\text { Multivariable Cox } \\
\text { Regression }\end{array}$} \\
\hline \multicolumn{5}{|c|}{ First damage accrued (any increase in $\mathrm{SDI}^{\mathrm{a}}$ ) } \\
\hline VARIABLE & $\begin{array}{l}\text { Hazard Ratio } \\
(95 \% \mathrm{Cl})\end{array}$ & $P$ value & $\begin{array}{l}\text { Hazard Ratio } \\
(95 \% \mathrm{Cl})\end{array}$ & $P$ value \\
\hline Age at first visit & $1.02(1.01-1.03)$ & $<0.001$ & $1.02(1.01-1.03)$ & $<0.001$ \\
\hline $\begin{array}{l}\text { Caucasian vs non- } \\
\text { caucasian }\end{array}$ & $0.88(0.71-1.08)$ & 0.22 & $0.89(0.72-1.11)$ & 0.31 \\
\hline $\begin{array}{l}\text { EULAR/ACR score }<\text { or } \\
\geq 20\end{array}$ & $1.21(0.98-1.48)$ & 0.07 & $1.3(1.04-1.57)$ & 0.02 \\
\hline \multicolumn{5}{|c|}{ First damage accrued (Initial SDI $\left.{ }^{\mathrm{a}}>0\right)^{\#}$} \\
\hline Age at first visit & $1.02(1.01-1.03)$ & $<0.001$ & $1.02(1.02-1.03)$ & $<0.001$ \\
\hline $\begin{array}{l}\text { Caucasian vs non- } \\
\text { caucasian }\end{array}$ & $0.88(0.71-1.10)$ & 0.27 & $0.91(0.73-1.14)$ & 0.42 \\
\hline $\begin{array}{l}\text { EULAR/ACR score }<\text { or } \\
\geq 20\end{array}$ & $1.25(1.01-1.54)$ & 0.04 & $1.33(1.07-1.64)$ & 0.009 \\
\hline \multicolumn{5}{|c|}{ Mortality } \\
\hline Age at first visit & $1.05(1.03-1.06)$ & $<0.001$ & $1.05(1.03-1.07)$ & $<0.001$ \\
\hline $\begin{array}{l}\text { Caucasian vs non- } \\
\text { caucasian }\end{array}$ & $1.46(0.84-2.57)$ & 0.17 & $1.48(0.84-2.62)$ & 0.17 \\
\hline $\begin{array}{l}\text { EULAR/ACR score }<\text { or } \\
\geq 20\end{array}$ & $1.66(1.01-2.73)$ & 0.04 & $2.13(1.28-3.54)$ & 0.003 \\
\hline
\end{tabular}

\#57 patients who had damage at entry were excluded for the analysis. aLICC/ACR Damage Index.

with a score $\geq 20$, (table 2 ). Individuals in the $\geq 20$ group had twice the probability of dying compared to patients with the lower score, the hazard ratios with significant $p$ values confirmed this finding (table 3).

Conclusion A EULAR/ACR score $\geq 20$ is an indicator of damage accrual and mortality in SLE.

\section{FACTORS IN LUPUS DIAGNOSIS}

${ }^{1}$ Daria McClamb*, ${ }^{2}$ Lydia Oberholtzer, ${ }^{1}$ Ashley Marion, 'Lauren Topf, 'Mary Crimmings, 'Karin Tse, ${ }^{3}$ John Wegener, ${ }^{3}$ Valerie Melucci, ${ }^{3}$ Tyler O'Malley, ${ }^{3}$ Debra Zack, ${ }^{4}$ Donald E Thomas. 'Lupus Foundation of America, Washington, DC; ${ }^{2}$ Sharp Insight, Montgomery County, Maryland; ${ }^{3}$ Exagen Inc., Vista, CA; ${ }^{4}$ Arthritis and Pain Associates of PG County

\subsection{6/lupus-2021-lupus21 century.77}

Background Lupus is a complex, chronic autoimmune disease affecting an estimated 1.5 million Americans.

Lupus symptoms are heterogeneous. Suboptimal diagnostic tests have contributed to diagnostic delay. Reducing diagnostic time is critical to preventing poor long-term outcomes. An objective of the 2020 survey sought to understand how access to healthcare is associated with diagnostic delay factors.

Methods A 25-question retrospective cross-sectional online survey on diagnostic time factors was developed by the Lupus Foundation of America (LFA) in partnership with Exagen. Using convenience sampling, individuals who self-reported SLE were recruited and 1,313 responded. Descriptive statistics and chi-square tests were conducted.

Results Almost half of respondents (45.4\%) were diagnosed within a year of their first health care provider visit to discuss symptoms, while $29.1 \%$ reported five or more years to diagnosis. Factors delaying diagnosis may include misdiagnosis and the number of visited doctors. On average, respondents saw 2.8 different types of doctors before diagnosis. Nearly a third reported they were diagnosed with anxiety (31.7\%), depression $(29.8 \%)$, or fibromyalgia $(23.0 \%)$ before their lupus diagnosis, and $21.8 \%$ were told nothing was wrong with them.

Decreased care access and high costs associated with delayed lupus diagnosis. More than a third (35.9\%) of respondents diagnosed after five or more years reported that out-of-pocket costs were too high, compared to $22.8 \%$ diagnosed within a year (table 1). Over half diagnosed after a year cited long wait times for specialist appointments,

Abstract 1304 Table 1 Challenges to Care in Lupus Diagnosis and Time to Diagnosis (N-1,302)

\begin{tabular}{|c|c|c|}
\hline Challenge Reported & Percent of Respondents (\%) & P-value \\
\hline Out-of-pocket costs too high & & 0.001 \\
\hline$<1$ year & 22.8 & \\
\hline $1-4$ years & 35.2 & \\
\hline $5+$ years & 35.9 & \\
\hline Long wait times for specialists & & 0.001 \\
\hline$<1$ year & 39.4 & \\
\hline $1-4$ years & 55.4 & \\
\hline $5+$ years & 58.3 & \\
\hline Insurance did not cover costs of services & & 0.003 \\
\hline$<1$ year & 8.6 & \\
\hline $1-4$ years & 13.9 & \\
\hline $5+$ years & 15.3 & \\
\hline Long wait times for PCP & & 0.001 \\
\hline$<1$ year & 8.3 & \\
\hline $1-4$ years & 15.4 & \\
\hline $5+$ years & 17.2 & \\
\hline Not enough doctors nearby to treat Lupus & & 0.03 \\
\hline$<1$ year & 25.2 & \\
\hline $1-4$ years & 32.2 & \\
\hline $5+$ years & 31.9 & \\
\hline
\end{tabular}


compared to $39.4 \%$ of those diagnosed within a year. Respondents diagnosed after a year were more likely to report insurance not covering costs, long wait times for appointments with primary care physicians (PCP), and lack of nearby doctors treating lupus.

Conclusion Multiple factors associated with lupus diagnosis delays, including delayed access to specialists, onerous health care costs, and health insurance obstacles. An ongoing shortage of rheumatologists may further magnify the delay in diagnosis and explain the apparent long wait times for specialists, misdiagnosis, and increasing costs. Further practitioner education, rheumatology provider recruitment, and studies examining reasons for lupus diagnosis delays may help us better understand and reduce inequities in reaching a prompt lupus diagnosis.

It is important to recognize the limitations of the study; the convenience sample study design lacks the rigor of random sampling, some questions may have introduced recall bias, and socioeconomic status and disease burden at time of diagnosis weren't addressed in this survey.

Acknowledgments The Lupus Foundation of America received funding from Exagen Inc. to support study data collection.

\section{0 - Lupus-targeted therapeutics}

\section{EFFECTS OF ANIFROLUMAB ON RENAL DISEASE IN PATIENTS WITH SYSTEMIC LUPUS ERYTHEMATOSUS}

${ }^{1}$ Eric F Morand*, ${ }^{2}$ Richard A Furie, ${ }^{3}$ Yoshiya Tanaka, ${ }^{4}$ Tsutomu Takeuchi, ${ }^{5}$ Gabriel Abreu, ${ }^{6}$ Raj Tummala, ${ }^{5}$ Catharina Lindholm. ${ }^{1}$ Monash University, Melbourne, VIC, Australia; ${ }^{2}$ Zucker School of Medicine at Hofstra/Northwell, Great Neck, NY, USA; ${ }^{3}$ University of Occupational and Environmental Health, Japan, Kitakyushu, Japan; ${ }^{4}$ Keio University School of Medicine, Tokyo, Japan; ${ }^{5}$ BioPharmaceuticals RandD, AstraZeneca, Gothenburg, Sweden; ${ }^{6}$ BioPharmaceuticals RandD, AstraZeneca, Gaithersburg, MD, USA

\subsection{6/lupus-2021-lupus21century.78}

Background The type I interferon (IFN) receptor antibody, anifrolumab, has shown efficacy in patients with systemic lupus erythematosus (SLE) in the phase 3 TULIP-1 and TULIP-2 trials. Type I IFN dysregulation is associated with lupus nephritis (LN) pathogenesis. Pooled TULIP data were analyzed to assess baseline characteristics of patients with and without renal involvement and to evaluate the effects of anifrolumab on renal disease.

Methods TULIP-1 and TULIP-2 were randomized, placebo-controlled trials of intravenous anifrolumab in patients with moderate to severe SLE despite standard therapy, which excluded patients with severe active LN. Renal involvement at baseline was defined as any of the following: British Isles Lupus Assessment Group(BILAG)-2004 renal score A-C; SLE Disease Activity Index 2000 (SLEDAI-2K) renal score >0; urine protein-creatinine ratio (UPCR) $>0.5 \mathrm{mg} / \mathrm{mg}$. Baseline characteristics were evaluated in patients with and without renal involvement, and the following endpoints were compared for the anifrolumab $300 \mathrm{mg}$ and placebo groups: cumulative UPCR (area under the curve, AUC) through Week (W)52; percentage of patients with UPCR $>0.5 \mathrm{mg} / \mathrm{mg}$ at baseline who improved to UPCR $\leq 0.5 \mathrm{mg} / \mathrm{mg}$ at W52; cumulative glucocorticoid (GC) use (AUC) through W52; and percentage changes in complement $\mathrm{C} 3 / \mathrm{C} 4$ from baseline to W52.

Results Of the 726 patients in TULIP-1/-2 (anifrolumab, $\mathrm{n}=360$; placebo, $\mathrm{n}=366$ ), 99 had renal involvement at baseline (anifrolumab, $\mathrm{n}=45$; placebo, $\mathrm{n}=54$ ), 57 of whom had
Abstract 1401 Table 1 Renal endpoints in TULIP-1 and TULIP-2

\begin{tabular}{|c|c|c|}
\hline Endpoint (baseline to Week 52) & Placebo & Anifrolumab $300 \mathrm{mg}$ \\
\hline \multicolumn{3}{|l|}{ UPCR AUC ${ }^{\mathrm{a}}$} \\
\hline $\mathrm{n}$ & 54 & 45 \\
\hline LS mean (SE) & $271.8(54.8)$ & $217.7(60.0)$ \\
\hline LS mean difference (SE), 95\% Cl & \multicolumn{2}{|c|}{$-54.1(54.3),-161.9,53.6$} \\
\hline \multicolumn{3}{|c|}{ Improvement from $>0.5$ to $\leq 0.5 \mathrm{mg} / \mathrm{mg}$ UPCR $^{\mathrm{b}}$} \\
\hline n & 33 & 24 \\
\hline Patients with improvement (\%) & 36.3 & 41.2 \\
\hline Difference, $\%$ (SE), $95 \% \mathrm{Cl}$ & \multicolumn{2}{|c|}{$4.9(13.3),-21.1,30.9$} \\
\hline \multicolumn{3}{|l|}{ Glucocorticoid AUC ${ }^{\mathrm{a}}$} \\
\hline n & 54 & 45 \\
\hline LS mean (SE) & $3524.5(339.0)$ & $3314.2(365.2)$ \\
\hline LS mean difference (SE), 95\% Cl & \multicolumn{2}{|c|}{$-210.3(332.6),-870.7,450.1$} \\
\hline \multicolumn{3}{|l|}{ Change in $\mathrm{C} 3 / \mathrm{C}_{4}(\%)^{\mathrm{c}}$} \\
\hline \multicolumn{3}{|l|}{ C3 } \\
\hline $\mathrm{n}$ & 31 & 21 \\
\hline Mean (SE) & $20.3(6.2)$ & $26.6(5.0)$ \\
\hline \multicolumn{3}{|l|}{ C4 } \\
\hline $\mathrm{n}$ & 19 & 14 \\
\hline Mean (SE) & $29.1(12.0)$ & $38.7(13.8)$ \\
\hline
\end{tabular}

AUC, area under the curve; $\mathrm{Cl}$, confidence interval; $\mathrm{LS}$, least squares; UPCR, urine proteincreatinine ratio; $\mathrm{SE}$, standard error;n, number satisfying baseline inclusion criteria for subgroup.

aPatients with baseline renal involvement; analysis of covariance.

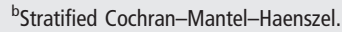

'Patients with renal involvement and abnormal C3/C4 at baseline.

UPCR $>0.5 \mathrm{mg} / \mathrm{mg}$ (anifrolumab, $\mathrm{n}=24$; placebo, $\mathrm{n}=33$ ). Patients with vs without renal involvement had a lower mean age (37.8 vs 42.4 years) and were more likely to be male (14.1\% vs 6.1\%), Asian (16.2\% vs 9.6\%), IFN gene signature high $(89.9 \%$ vs $81.5 \%)$, and anti-dsDNA positive $(69.7 \%$ vs 40.4\%); have a SLEDAI-2K score $\geq 10 \quad(91.9 \%$ vs $68.4 \%)$; and be receiving GC $\geq 10 \mathrm{mg} /$ day $(67.7 \%$ vs $49.1 \%)$ or mycophenolate $(26.3 \%$ vs $11.5 \%)$ at baseline. Among patients with baseline renal involvement, anifrolumab treatment was associated with a greater improvement vs placebo in cumulative UPCR (AUC) through W52 (table 1). More patients improved from UPCR $>0.5 \mathrm{mg} / \mathrm{mg}$ at baseline to $\leq 0.5 \mathrm{mg} / \mathrm{mg}$ at W52 with anifrolumab vs placebo (table 1). Among patients with renal involvement, cumulative GC use (AUC) through W52 was lower with anifrolumab vs placebo and there were greater improvements in C3/C4 from baseline to W52 (table 1).

Conclusions TULIP data suggest renal benefit with anifrolumab in patients with SLE with mild/stable renal disease, supporting further investigation into anifrolumab's efficacy in patients with active LN.

Acknowledgments Writing assistance by Rosie Butler, PhD, of JK Associates Inc., part of Fishawack Health. This study was sponsored by AstraZeneca.

Trial Registration NCT02446912 and NCT02446899

\section{AUGMENTED GLUCOSE DEPENDENCY OF AUTOREACTIVE B CELLS PROVIDES A TREATMENT TARGET FOR LUPUS}

${ }^{1}$ John J Wilson, ${ }^{1}$ Jian Wei, ${ }^{2}$ Andrea R Daamen, 'John D Sears, 'Elaine Bechtel, ${ }^{1}$ Colleen L Mayberry, ' Grace A Stafford, ${ }^{2}$ Amrie C Grammer, ${ }^{2}$ Peter E Lipsky, ${ }^{1}$ Derry C Roopenian,

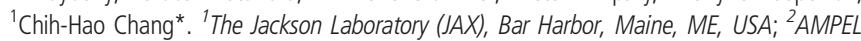
BioSolutions and the RILITE Research Institute, Charlottesville, VA, USA

10.1136/lupus-2021-lupus21century.79 